\title{
ULTRA-SOFT X-RAY ABSORPTION SPECTROSCOPY: A BULK AND SURFACE PROBE OF MATERIALS
}

DANIEL A. FISCHER*, GARY E. MITCHELL**, BENJAMIN M. DEKOVEN**, ALVIN T. YEH***, JOHN L. GLAND***, AND ARNIE R. MOODENBAUGH****

* National Institute of Standards and Technology, Gaithersburg, MD 20899

**The Dow Chemical Company, Midland, MI 48667

* ' The University of Michigan, Ann Arbor, MI 48109

****Brookhaven National Laboratory, Upton, NY 11973

\section{ABSTRACT}

Direct comparisons between the surface and bulk of diverse materials can be made by simultaneous electron yield ( $5 \mathrm{~nm}$ depth sensitivity) and fluorescence yield ( $200 \mathrm{~nm}$ ) ultra soft $\mathrm{x}$-ray absorption spectroscopy measurements utilizing a rapid sample interchange apparatus. For example the orientations of functional groups have been characterized at and near the surface of a series of model polymeric materials highlighting the chemical and molecular sensitivity of ultra soft $\mathrm{x}$-ray absorption spectroscopy. In addition we discuss a bulk sensitive use of fluorescence yield to non destructively study a buried metal polymer interface. A second bulk sensitive example is the use of fluorescence yield oxygen $\mathrm{K}$ near edge $\mathrm{x}$-ray spectroscopy as a method to determire the hole state density of high Tc materials.

\section{INTRODUCTION}

Ultra soft $x$-ray absorption spectroscopy (USXAS) is an important extension of a traditionally hard $x$-ray technique for structural determination of low $Z$ elements $(C, N, O, F)$ in materials. Until recently USXAS studies have been accomplished solely by electron yield methods which usually must be done under ultra high vacuum conditions [1]. Although the fluorescence yield for low $\mathrm{Z}$ elements is very small (e.g. .0012 for carbon) the technical challenge of the technique opens an opportunity for the development of an in situ photon-in photon-out structural probe. The technique is particularly useful in surface chemistry applications for in situ monitoring (kinetics) of transient surface species under real reaction conditions of temperature and pressure $[2,3,4,5]$. We have developed an ultra high vacuum compatible system for measuring low Z fluorescence USXAS over a broad pressure range; $10-10$ mbar to several atmospheres [6]. Such a system allows the USXAS technique to address a range of materials problems from monolayers to bulk materials (including insulators such as polymers and diamond) even in the presence of a reactive gas atmosphere. Direct comparisons between the surface and bulk of diverse materials can be made by simultaneous electron yield (50 $\mathrm{nm}$ depth sensitivity) and fluorescence yield $(200 \mathrm{~nm})$ measurements utilizing a rapid sample interchange apparatus [6]. For example the orientation of phenyl rings in spin coated polystyrene has been characterized at and near the surface for a series of molecular weights(MW) and casting solvents highlighting the chemical and molecular sensitivity of USAXS [7]. The bulk sensitivity of fluorescence yield has been utilized to study a buried metal polymer interface, highlighting the use of USXAS to provide new detailed chemical information which will be useful in predicting and optimizing the adhesion in metal / polymer interfaces. A second bulk-sensitive example is the use of fluorescence-yield oxygen $K$ near edge $x$-ray spectroscopy as a method to determine the hole state density of high Tc materials. A pre-edge peak occurs just above the Fermi level which can be assigned to holes in the oxygen $2 \mathrm{p}$ band. The intensity of this peak was determined as a function of composition in high Tc materials $[8,9]$.

\section{POLYMERS}

\section{Polystyrene: Surface Versus Bulk}

The experiments described were performed on the U1 beam line at the National Synchrotron Light Source, Brookhaven National Laboratory. The estimated total photon flux was about $1 \times 10^{10}$ per second at $300 \mathrm{eV}$ photon energy with a resolution of $0.6 \mathrm{eV}$. Typical storage ring currents were in the $400-600 \mathrm{~mA}$ range during these experiments. The ultra soft $\mathrm{x}$ ray absorption spectra were collected with a rapid sample interchange system equipped with 
facilities for simultaneous fluorescence yield and partial electron yield detection described fully in reference 6 . Thin polystyrene samples were spin cast from toluene or methylene chloride (HPLC grade) solvent solutions (approximately 0.3 weight percent) onto $200 \mathrm{~nm}$ gold films under coated with $5 \mathrm{~nm}$ of Ti on $15 \times 15 \mathrm{~mm}$ squares of $\mathrm{Si}(100)$ wafers, $1.0 \mathrm{~mm}$ thick. Samples of various thicknesses were prepared by spin coating the polymer from different concentration solutions. The resulting polymer thickness was estimated using $x$-ray photoelectron spectroscopy (XPS) and should be considered to have absolute uncertainties on the order of the electron mean free path $(5 \mathrm{~nm}$ in this case). Figure 1 shows a typical fluorescence yield (FY) carbon $\mathrm{K}$ near edge $\mathrm{x}$-ra, absorption spectrum of a spin-cast film of $35,000 \mathrm{MW}$ anionically polymerized polystyrene, $10 \mathrm{~nm}$ thick. The spectrum was fit to a combination of 5 Gaussian peaks and an edge step function to simulate the ionization threshold at $290 \mathrm{eV}$, after ruference 10 . There are three important pre-edge resonances in the spectrum of polystyrene, the $\mathrm{C}-\mathrm{C} \pi^{*} 1$ resonance at $285 \mathrm{eV}$, the $\mathrm{C}-\mathrm{H}^{*}$ resonance at $287 \mathrm{eV}$, and the $\mathrm{C}-\mathrm{C} \pi^{*} 2$ resonance at $288 \mathrm{eV}$ [10]. The $\pi^{*}$ resonances involve the excitation of a $1 \mathrm{~s}$ electron to unfilled $\pi^{*}$ antibonding orbitals on the aromatic ring. Higher in energy, above the ionization potential for the 1s electron, are the $\sigma^{*} 1$ and the $\sigma^{*} 2$ resonances. These resonances are excitations of the $1 \mathrm{~s}$ electron to the higher unoccupied molecular orbitals characteristic of $\sigma$ bonds. Included in the $\sigma^{*} 1$ resonance are also contributions from the main chain $\sigma$-bonds [11]. Since no resonant excitations are detected above the $\sigma^{*} 2$ peak, the excitations above $300 \mathrm{eV}$ involve transitions to the continuum and will be independent of the chemical state of the carbon atoms which are under study. Thus the intensity at $325 \mathrm{eV}$ is used below as a convenient measure of the total amount of carbon present in the probed volume.

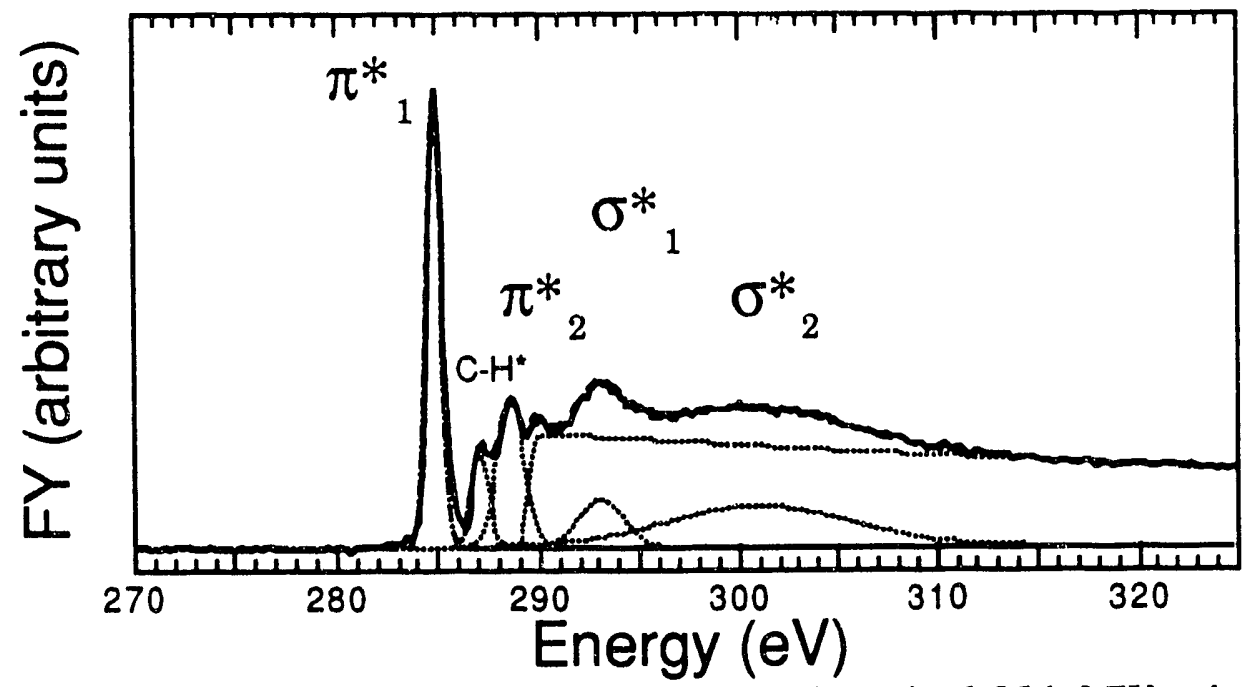

Figure 1. Fluorescence yield spectrum of anionically polymerized $35 \mathrm{k} \mathrm{MW}$ polystyrene at normal photon incidence. The dashed line corresponds to the fitted spectrum which is a sum of the constituent peaks shown with the dotted lines. $\pi^{*} 1$ and $\pi^{*} 2$ are resonances to antibonding orbitals of the aromatic functional group characteristic of the double bonds. $\sigma^{*} 1$ and $\sigma^{*} 2$ are resonances of antibonding orbitals of the phenyl ring characteristic of the single bonds. $\sigma^{*} 1$ also has contributions from the main chain. The unmarked peak at $290 \mathrm{eV}$ is a result of the overlap of the edge jump and the $\pi^{*} 2$ resonance.

A comparison of polystyrene FY carbon $\mathrm{K}$ near edge spectra taken with a normal ( 90 degree) and glancing ( 25 degree) incidence (with respect to the sample surface) photon beam are shown in figure 2 . The $\pi^{*}$ peak appears more intense for the normal geometry than in the glancing incidence case. At normal incidence the electric field vector of the incident radiation is parallel to the surface. Since the $\pi^{*}$ orbitals in the phenyl rings of polystyrene are perpendicular to the ring this result indicates that the phenyl rings are preferentially tilted towards the surface normal. Both EY and FY near edge spectra of the spin coated films indicate that the plane of the phenyl rings were oriented towards the surface normal of these thin polymer films. 


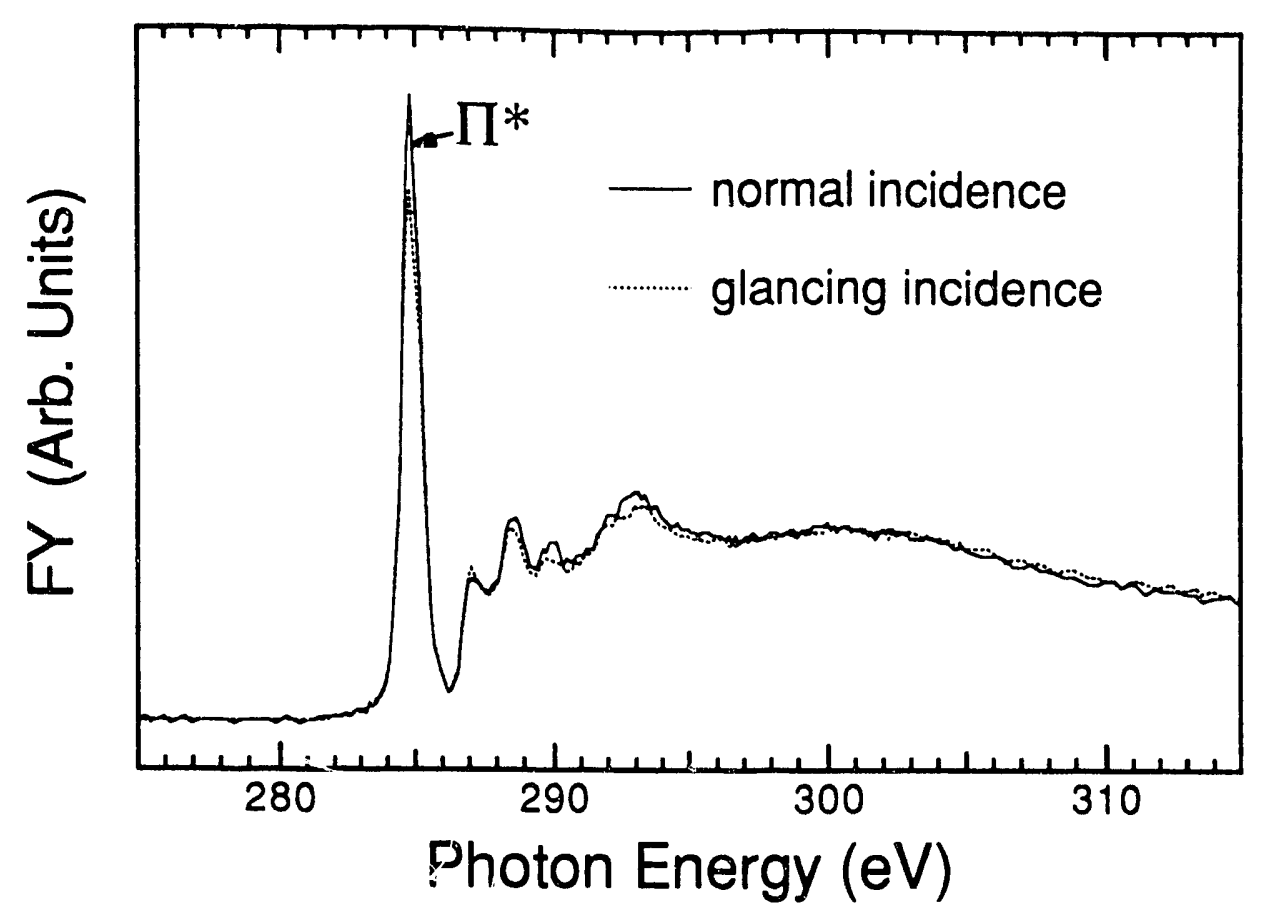

Figure 2. FY spectra of $35 \mathrm{~K}$ molecular weight polystyrene at both normal and glancing photon incidence. By comparing the intensity of the $\pi^{*}{ }_{1}$ resonance, a preferential spatial orientation of the aromatic functional group toward the surface normal is apparent.

In figure 3 we plot the intensity ratio of the $\pi^{*}$ peak ( $285 \mathrm{eV}$, polystyrene phenyl ring) to the intensity at $325 \mathrm{eV}$ as a function of film thickness for EY and FY in normal and glancing incidence. Normalization by the intensity at $325 \mathrm{eV}$ allows the spectra of all film thicknesses to be directly compared independent of total carbon content. For the FY data (shaded symbols), the ratios decrease with increasing thickness, but more quickly for normal incidence then glancing. For EY data (open symbols), the ratio appears to remain constant with thickness (unfortunately, for the thickest samples at normal incidence the EY spectrum suffered from surface charging effects and the data was unreliable). In both FY and EY, the ratios for normal incidence are always larger than that at glancing incidence. This anistropy is indicative of a preferential orientation of the phenyl ring plane towards the surface normal for all film thicknesses. The decrease in anisotropy with thickness observed in FY is also consistent with what would be expected if the preferential orientation of the phenyl rings were due to a surface effect. But if the latter were the case, the ratios in FY for the extremely thin case should extrapolate back to the same value as for EY. In fact the FY ratios show more anisotropy for the thinnest case than is apparent in EY. This suggests that the film is slightly relaxed at the surface and less oriented. Vilar at al have suggested from HREELS results that the end groups of polystyrene molecules tend to segregate to the surface of spin coated films $[12,13]$. An increase in the number of end groups at the surface would also be consistent with our data. For these spin cast polystyrene thin films the pendant phenyl groups are found to be preferentially oriented toward the surface plane normal, independent of casting solvent, molecular weight, and film thickness.

\section{DISCLAIMER}

\footnotetext{
This report was prepared as an account of work sponsored by an agency of the United States Government. Neither the United States Government nor any agency thereof, nor any of their employees, makes any warranty, express or implied, or assumes any legal liability or responsibility for the accuracy, completeness, or usefulness of any information, apparatus, product, or process disclosed, or represents that its use would not infringe privately owned rights. Reference herein to any specific commercial product, process, or service by trade name, trademark, manufacturer, or otherwise does not necessarily constitute or imply its endorsement, recommendation, or favoring by the United States Government or any agency thereof. The views and opinions of authors expressed herein do not necessarily state or reflect those of the United States Government or any agency thereof.
} 


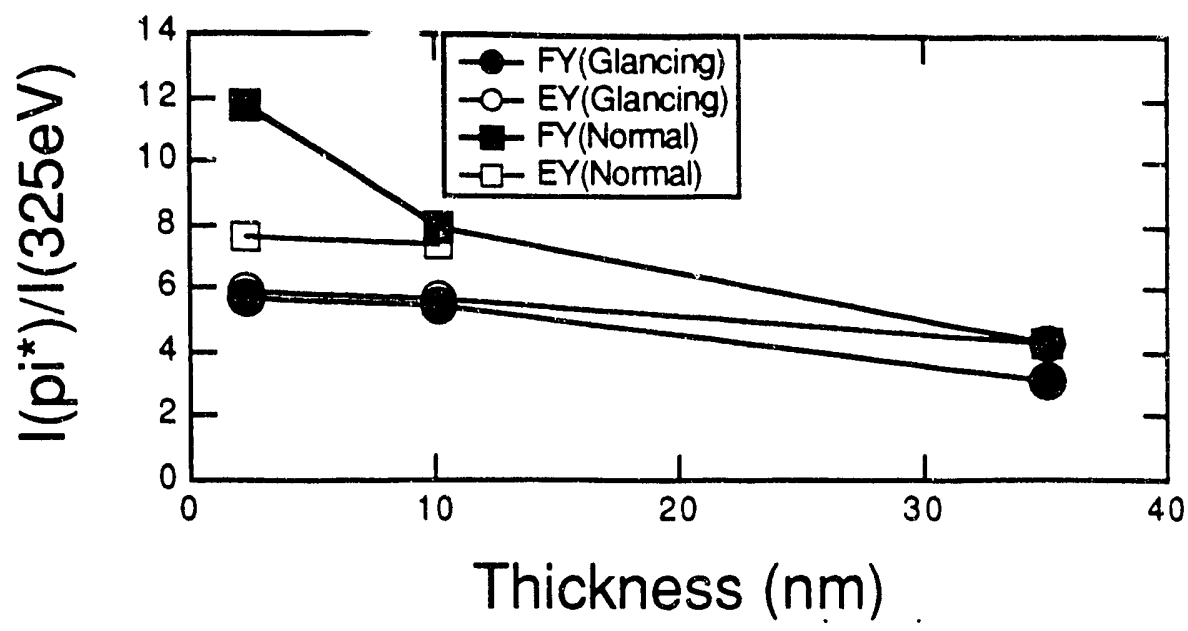

Figure 3. Comparison of the ratio of the $\pi^{*} 1$ to the intensity at $325 \mathrm{eV}$ at normal and glancing incidence angles and for EY and FY versus thickness. This graph illustrates an apparent preferential spatial orientation of the phenyl ring normal to the surface plane and illustrates the variation in relative intensities with film thickness.

In thin films, one may consider two possible reasons for the preferential orientation of the phenyl rings: Orientation may occur by either (1) the effect of surface forces directly on the aromatic rings, or (2) because of an effect on the overall polymer chain which is then transmitted to the aromatic rings (ie. the rings have a more or less defined orientation relative to the chain axis). We believe the latter is the case for the following reasons. If the orientation of the phenyl rings were exclusively a surface effect, there would be more anisotropy in the EY than the FY spectrum and this is not observed. If the polymer were randomly oriented relative to the surface, or if the phenyl rings were randomly oriented in the polymer, the $\pi^{*}$ intensity would be independent of the angle of incidence of the $x$-ray beam. The fact that anisotropy is observed, is good evidence for both preferential orientation of the phenyl rings relative to the polymer axis and orientation of the polymer axes relative to the surface plane of the film. Preferential orientation of the phenyl rings with respect to the chain axis in polystyrene is consistent with what one surmises from examination of space-filling models of the polymer.

\section{DVS bis-BCB (divinyl siloxane bis-benzocyclobutene): Buried Metal / Polvmer Interface}

DVS bis-BCB (divinyl siloxane bis-benzocyclobutene) is used for dielectric layers in new generation multilayer interconnect devices (multi-chip modules) [14]. For this application it is important to understand the nature of the bonding and complexing which occurs at the metal / polymer interface. The depth sensitivity (about $200 \mathrm{~nm}$ ) and the non destructive nature of fluorescence yield are particularly useful in studying the buried interface between DVS bis-BCB coated with aluminium (10 to $100 \mathrm{~nm})$ [15]. In contrast the relatively short depth sensitivity of traditional electron yield USXAS makes it useless for the buried interface study, since it would only probe the outer $5 \mathrm{~nm}$ of the aluminium overlayer. We have collected FY carbon $\mathrm{K}$ near edge spectra for evaporated aluminum coated ( $50 \mathrm{~nm}$ thick) DVS bis-BCB ( $50 \mathrm{~nm}$ thick) as well as the identical bare polymer. Figure 4, upper and lower panels show these normalized spectra for normal and glancing incident $x$-rays respectively. In order to enhance the metal / polymer interface sensitivity each panel shows a difference plot (coated polymer minus bare polymer). The C-C $\pi^{*}$ peak $(286 \mathrm{eV})$ of the aromatic ring of DVS bis-BCB in the difference plots appears to undergo a dramatic enhancement in polarization dependance after the formation of the metal / polymer interface. This polarization enhancement at the interface region implies that the aromatic ring planes of DVS bis-BCB are highly oriented towards the surface normal. These preliminary results highlight the use of ultra soft $x$-ray absorption spectroscopy to provide new detailed chemical information which may be useful in predicting and optimizing the adhesion in metal / polymer interfaces. 

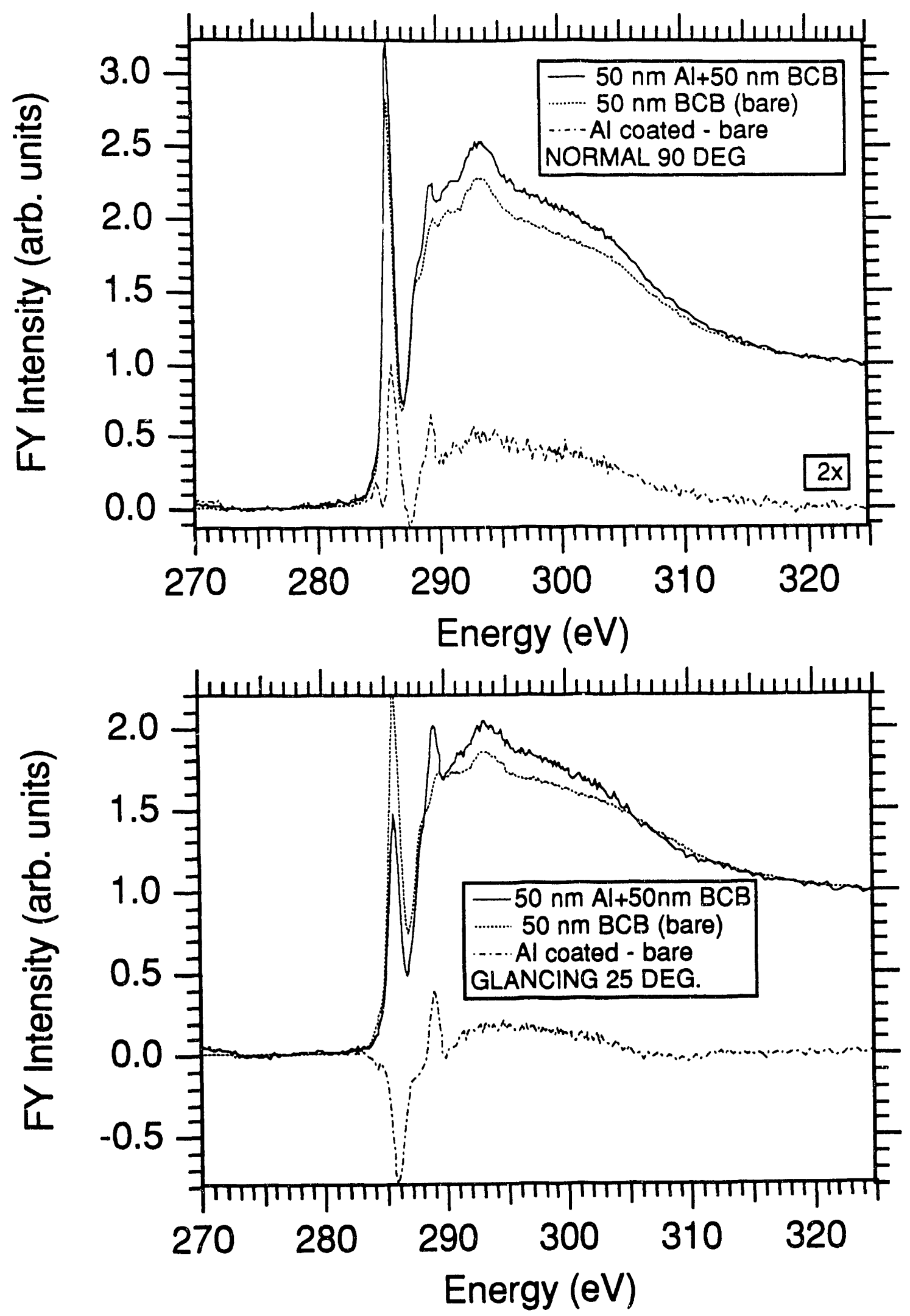

Figure 4. FY carbon $\mathrm{K}$ near edge spectra for evaporated aluminum coated ( $50 \mathrm{~nm}$ thick) DVs bis-BCB (50 nm thick) as well as the identical bare polymer, upper and lower panels show spectra for normal and glancing incident $x$-rays respectively. In order to enhance the metal / polymer interface sensitivity each panel shows a difference plot (coated polymer minus bare polymer). 


\section{ACKNOWLEDGMENTS}

The authors would like to acknowledge Craig Fulks, Scott Kisting, Ted Stokich, and Paul Townsend (all from The Dow Chemical Co.) for preparing the DVS bis-BCB samples. We would also like to acknowledge Jim Curphy and Mike Radler (both from The Dow Chemical Co.) for helping to take some of the data presented here. A.R. Moodenbaugh was supported by the U.S. Department of Energy under Contract No. DE-AC02-76CH00016.

\section{REFERENCES}

1. D.A. Fischer, U. Dobler, D. Arvanitis, L. Wenzel, K. Baberschke, and J. Stohr, Surf. Sci. 177, 114-120 (1986).

2. F. Zaera, D.A. Fischer, J.L. Gland, and S. Shen, Surf. Sci. 194, 205-16(1988).

3. J.L. Gland, D.A. Fischer, F. Zaera, and S. Shen, in Catalysis 1987, (Studies in Surface Science and Catalysis V38), ed. J. Ward, Elsevier, 835-43(1988).

4. D.H. Parker, D.A. Fischer, J. Colbert, B.E. Kor ı, and J.L. Gland, Surf. Sci. Letters 235, L372-L376 (1990).

5. D.H. Parker, D.A. Fischer, J. Colbert, B. Koel, J.L. Gland, Surf. Sci. 258,75-81(1991).

6. D.A. Fischer, J. Colbert, and J.L. Gland, Rev. of Sci. Inst. 60, 1596-1602 (1989).

7. A.T. Yeh, J.L. Gland, D.A. Fischer, G.E. Mitchell, in preperation for Langmuir.

8. C.Y. Yang, A.R. Moodenbaugh, Y. Xu, Y.L. Wang, M. Suenagua, and D.A. Fischer, Phys. Rev. B. 42, 2231-41 (1990).

9. D. A. Fischer, A. R. Moodenbaugh, and Youwen Xu for submission to Physical Review B.

10. J. A. Horsley, J. Stohr, A. P. Hitchcock, D. C. Newbury, A. L. Johnson and F. Sette, J. Chem. Phys., 83, 6099(1985).

11. D. Outka and J. Stohr, J. Chem. Phys., 88, 3539(1988).

12. M. Rei Vilar, M Scott, J.J. Pireaux, C. Gregoire, P.A. Tlury, R. Caudano, A. Lapp, A. M. Bitclho Do Rego, J. Lopes Da Silva, Surface Science, 189/190, 927-934(1987).

13. M. Rei Vilar, M. Schott, J.J. Pireaux, C. Gregoire, R. Caudano, A. Lapp, J. Lopes Da Silva, A. M. Botelho Do Rego, Surface Science, 211/212, 782-789(1990).

14. T.M. Stokich, Jr., W.M. Lee and R.A. Peters, Materials Research Society Proceedings 227, 103(1991).

15. Manuscript in preperation for submission to Science. 

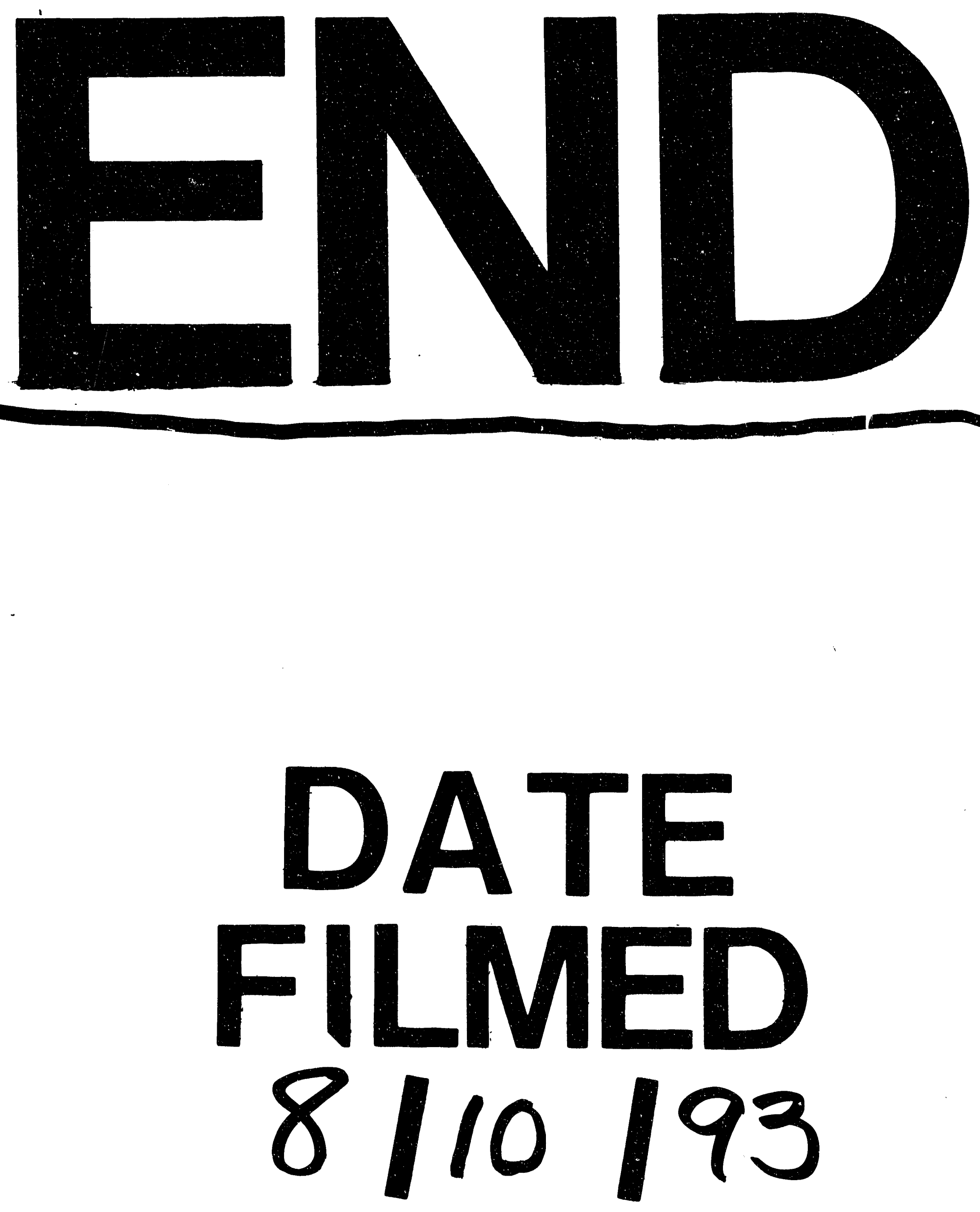

$\stackrel{\underline{3}}{\bar{n}}$ 
